Article

\title{
Genetic Mapping Identifies Consistent Quantitative Trait Loci for Yield Traits of Rice under Greenhouse Drought Conditions
}

\author{
Niranjan Baisakh ${ }^{1, * \mathbb{D}}$, Jonalyn Yabes ${ }^{1, \dagger}$, Andres Gutierrez ${ }^{1, \dagger}$, Venkata Mangu ${ }^{1,+, \S}$, \\ Peiyong Ma ${ }^{1, \ddagger}$, Adam Famoso ${ }^{2}$ and Andy Pereira ${ }^{3}$ (i) \\ 1 School of Plant, Environmental and Soil Sciences, Louisiana State University Agricultural Center, Baton \\ Rouge, LA 70803, USA; jyabes@agcenter.lsu.edu (J.Y.); AGutierrezViveros@agcenter.lsu.edu (A.G.); \\ 77.ramana@gmail.com (V.M.); pma@agcenter.lsu.edu (P.M.) \\ 2 Rice Research Station, Louisiana State University Agricultural Center, Crowley, LA 70578, USA; \\ afamoso@agcenter.lsu.edu \\ 3 Department of Crop and Soil Sciences, University of Arkansas, Fayetteville, AR 72701, USA; \\ apereira@uark.edu \\ * Correspondence: nbaisakh@agcenter.lsu.edu; Tel.: +1-225-5781300 \\ $+\quad$ They contributed equally to this work. \\ $\ddagger$ Present address: Jiangsu Academy of Agricultural Sciences, Nanjing 210014, Jiangsu, China. \\ $\S$ Present address: Plastomics Inc., St. Louis, MO 63132, USA.
}

Received: 21 December 2019; Accepted: 3 January 2020; Published: 5 January 2020

\begin{abstract}
Improving drought resistance in crops is imperative under the prevailing erratic rainfall patterns. Drought affects the growth and yield of most modern rice varieties. Recent breeding efforts aim to incorporate drought resistance traits in rice varieties that can be suitable under alternative irrigation schemes, such as in a (semi)aerobic system, as row (furrow-irrigated) rice. The identification of quantitative trait loci (QTLs) controlling grain yield, the most important trait with high selection efficiency, can lead to the identification of markers to facilitate marker-assisted breeding of drought-resistant rice. Here, we report grain yield QTLs under greenhouse drought using an $\mathrm{F}_{2: 3}$ population derived from Cocodrie (drought sensitive) $\times$ Nagina 22 (N22) (drought tolerant). Eight QTLs were identified for yield traits under drought. Grain yield QTL under drought on chromosome 1 (phenotypic variance explained $(\mathrm{PVE})=11.15 \%$ ) co-localized with the only QTL for panicle number (PVE $=37.7 \%)$. The drought-tolerant parent N22 contributed the favorable alleles for all QTLs except $q$ GN3.2 and qGN5.1 for grain number per panicle. Stress-responsive transcription factors, such as ethylene response factor, WD40 domain protein, zinc finger protein, and genes involved in lipid/sugar metabolism were linked to the QTLs, suggesting their possible role in drought tolerance mechanism of N22 in the background of Cocodrie, contributing to higher yield under drought.
\end{abstract}

Keywords: drought; grain yield; greenhouse; panicle; QTL; rice

\section{Introduction}

The onset of widespread climate change is causing erratic rainfall patterns, leading to limited availability of surface water for irrigation in field crops, thus creating a water deficit or drought scenario in arid and semi-arid regions [1]. Rice is life to billions of people who depend on it as their primary source of calories. Rice production needs to be doubled in the next decade to meet the demand of the ever-increasing rice-consuming population. This has to be achieved with less land and without exhausting natural resources, including water [2]. Drought is considered the most devastating abiotic stress for rice, causing up to $50 \%$ yield loss worldwide [3]. Most modern high-yielding rice cultivars 
are drought sensitive, and the impact on yield is severe when the plants experience drought at the reproductive stage [4]. Therefore, it is important to breed drought-resistant rice varieties that are suitable for rainfed areas, which occupy almost half of the rice growing areas.

In the U.S., rice has historically been cultivated under irrigation because water is abundant, especially in Louisiana. However, freshwater availability can be affected by storm surge, which affects the quality of surface irrigation water by making it saline or alkaline. So, considering the importance of the shortage of quality ground and surface water available for irrigation, alternative water management strategies, such as alternate wetting and drying and furrow-irrigation (row rice) are being adopted as promising strategies to tackle future water shortages. Additionally, row rice production practices are gaining popularity as this practice requires fewer resources in field preparation and provides farmers with more flexibility when deciding which crop that they will produce. Therefore, efforts are underway for the development of drought-tolerant rice varieties with high water use efficiency that can fit to the alternate water management schemes, such as aerobic conditions [5].

The development of successful aerobic rice cultivars could be achieved by combining the high-yielding traits of irrigated rice with the drought-tolerant traits of traditional upland rice cultivars. Secondary drought resistance traits, such as relative water content, membrane stability index, leaf area, canopy temperature, root growth, etc., are difficult to quantify for their direct contribution to grain yield in a breeding population. On the other hand, grain yield traits under drought were considered to be consistent and most effective for the selection of drought-resistant rice genotypes [4,6].

Identification and introgression of quantitative trait loci (QTLs) controlling grain yield under drought are an effective approach to breeding high-yielding drought-resistant rice [7-9]. To this end, 16 grain yield under drought (GYD) QTLs on all but three rice chromosomes $[5,7,8]$ were reported [10]. However, a meta-QTL study identified 14 MQTLs on seven chromosomes including two on chromosome 8 for GYD [11]. The qDTY12.1 on chromosome 12 was the first QTL reported for grain yield under drought that is consistent over multiple generations [12], and it has been used to develop drought-resistant upland and lowland rice with increased grain yield $[13,14]$. The QTL qDTY1.1 on chromosome 1 was identified where drought-resistant varieties Nagina $22[15,16]$ and Dhagaddeshi [17] contributed the favorable allele for GYD. Two other QTLs, qDTY2.3 [18,19] and qDTY3.2 [20], from the variety Vandana interact with $q D T Y 12.1$ to enhance yield and harvest index under severe upland and lowland drought conditions [21]. Five GYD QTLs on chromosomes 1, 6, 8, 10, and 12 were identified [22], with the largest effect $q D T Y 12.1$ coinciding with a minor QTL for grain thickness [23].

Considering the narrow genetic base and drought sensitivity of the U.S. rice germplasm [24], introgression of drought-tolerant genes from drought-tolerant germplasm have been initiated into the background of rice varieties adapted to the southern U.S. [5,25]. Previously, we reported six QTLs (three on chromosome 1 and one each on chromosome 5, 8, and 9) contributing to grain yield under controlled greenhouse conditions, where the favorable alleles for four QTLs were contributed by the drought-tolerant donor variety Vandana [25]. Here, we report on the identification of genetic determinants for grain yield traits under greenhouse drought conditions in the same U.S. genetic background Cocodrie but with a different drought-resistant donor, Nagina 22.

\section{Materials and Methods}

\subsection{Mapping Population}

The population used in the present mapping study included $190 \mathrm{~F}_{2: 3}$ progeny lines derived from the $\mathrm{F}_{1} \mathrm{~s}$ between a US-bred drought-sensitive variety 'Cocodrie' [26] and an "Aus"-type Indian-origin drought-resistant Nagina 22 (N22). N22 is a short-duration (90-95 days), deep rooted, drought- and heat-tolerant "Aus" rice landrace [27]. 


\subsection{Drought Screening and Phenotypic Data Analysis}

Phenotyping of $190 \mathrm{~F}_{2: 3}$ progeny lines and the parents for their drought response was done inside the Louisiana State University Agricultural Center's greenhouse at Gourrier Ln, Baton Rouge, LA during spring 2015 and fall 2017 as previously described [25,28]. Briefly, two sets of six plants per line including parents were grown in $2.8 \mathrm{~L}$ plastic pots with bottom holes under normal irrigation. For drought stress, irrigation was withdrawn from one set of 45-day-old plants for two weeks (soil moisture content $\sim 0.07 \mathrm{~m}^{3} / \mathrm{m}^{3}$ ), while the other set was well watered (control; soil moisture content $0.48 \mathrm{~m}^{3} / \mathrm{m}^{3}$ ). Following drought, irrigation was resumed until grain maturity. The experiment was conducted in a complete randomized block design, with three replications in ceramic trays (blocks), as described earlier [25]. Data were recorded on both control and recovered plants for yield traits such as the number of panicles per plant, the number of grains per panicle, and grain yield (g) per plant.

Phenotypic data were analyzed using the basic R v3.4.1 package and SAS 9.3 [29] as described earlier [25,30]. Normality of the data was determined by the Shapiro-Wilk test and Pearson's test was conducted to estimate the correlations among the yield traits [30]. Analysis of variance (ANOVA) of the yield traits was estimated using mixed model (Proc MIXED). Broad-sense heritability was calculated on a family means basis using ANOVA-derived variance components. Frequency distribution of the yield traits under drought was charted as histogram using basic $R$ v3.4.1 package.

\subsection{Molecular Markers and Genotyping}

Markers used for genotyping consisted of 134 SSRs [31], four Indel markers [32], and six genic SSRs [25] that were polymorphic between Cocodrie and N22. In addition, eight polymorphic SNPs were used to narrow down the gaps in the QTL regions in chromosome 1, 8, and 11.

\subsection{Genotyping, Linkage and QTL Mapping}

Genotyping of the mapping population with the SSR and Indel markers was conducted on single $\mathrm{F}_{2}$ plants following Solis et al. [25]. SNP genotyping was performed using KASP markers on an LGC SNP genotyping platform following the manufacturer's instructions (https://biosearch-cdn.azureedge. net/assetsv6/KASP-genotyping-chemistry-User-guide.pdf).

Multipoint linkage analysis was performed using ICIM software v 4.0 [33], using a recombination frequency $(\mathrm{r})$ set at 0.45 . The map position (cM) of markers was estimated using the Kosambi mapping function and ordered with a threshold logarithm of odd (LOD) set at 3.0. QTL analysis with the mean data on yield and yield attributing traits of the $\mathrm{F}_{2: 3}$ progeny lines averaged over two years was conducted by interval mapping (IM) and inclusive composite interval mapping (ICIM). QTLs explaining $\geq 5 \%$ phenotypic variance with LOD $\geq 2.5$ were declared significant, and QTL nomenclature followed Solis et al. [25]. Genotypic frequency was calculated for yield trait loci using the marker closest to the QTL peak.

\subsection{The Identification of Candidate Genes in QTL Region}

Physical positions of the marker closest to a QTL was retrieved from Gramene (www.gramene.org) and inputted to identify the genes using SNP-Seek II [34]. Genes were compared to the set of genes that were significantly differentially expressed from the transcriptome study using N22 [35] and Vandana [25].

\section{Results}

\subsection{Genetic Variation for Grain Yield and Yield Traits under Drought}

The Cocodrie $\times$ N22 $\mathrm{F}_{2: 3}$ progenies showed variation in their phenotypic response such as leaf rolling, drying and wilting symptoms to drought stress (Figure 1). The average panicle number per plant, grains per panicle, and grain yield per plant of the stressed $F_{2: 3}$ lines were $1.7(0.14-9.00), 30$ 
(0.50-115.25), and $2.02 \mathrm{~g}(0.35-4.60)$, respectively (Supplementary Table S1). The parents, Cocodrie and N22 had contrasting responses under drought, where panicle number, grain number and grain yield per plant were 2.2, 44 and $2.6 \mathrm{~g}$, respectively, for Cocodrie, and 8.4, 93 and $12.1 \mathrm{~g}$, respectively, for N22 (Supplementary Table S1). The phenotypic distribution of all the yield traits studied under drought showed a (near)normal distribution (Figure 2) with $p$-values $0.041,<0.001$ and $<0.0001$, and W $=0.9964,0.9617$ and 0.9913 , respectively, for panicle number, grain number and grian yield (g).

The yield traits showed a significantly positive correlation among themselves (Supplementary Table S2). The correlation between grain yield per plant and grain number per panicle was significantly high $(0.89, p<0.01)$ followed by that between grain yield and panicle number per plant $(0.69, p<0.01)$. However, the correlation between panicle number and grain number was moderate $(0.34)$, yet significant $(p<0.01)$. The broad sense heritability $\left(H^{2}\right)$ for panicle number, grain number, and grain yield was moderately high at $0.68,0.55$, and 0.32 , respectively.

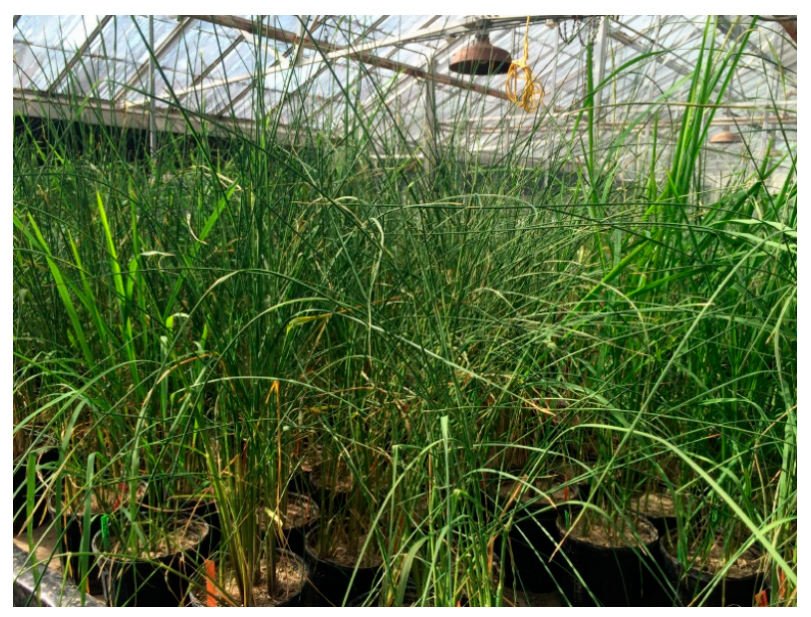

Figure 1. $F_{2: 3}$ progenies derived from Cocodrie $\times$ Nagina $22(\mathrm{~N} 22)$ showing segregation for drought response phenotypes under greenhouse conditions.
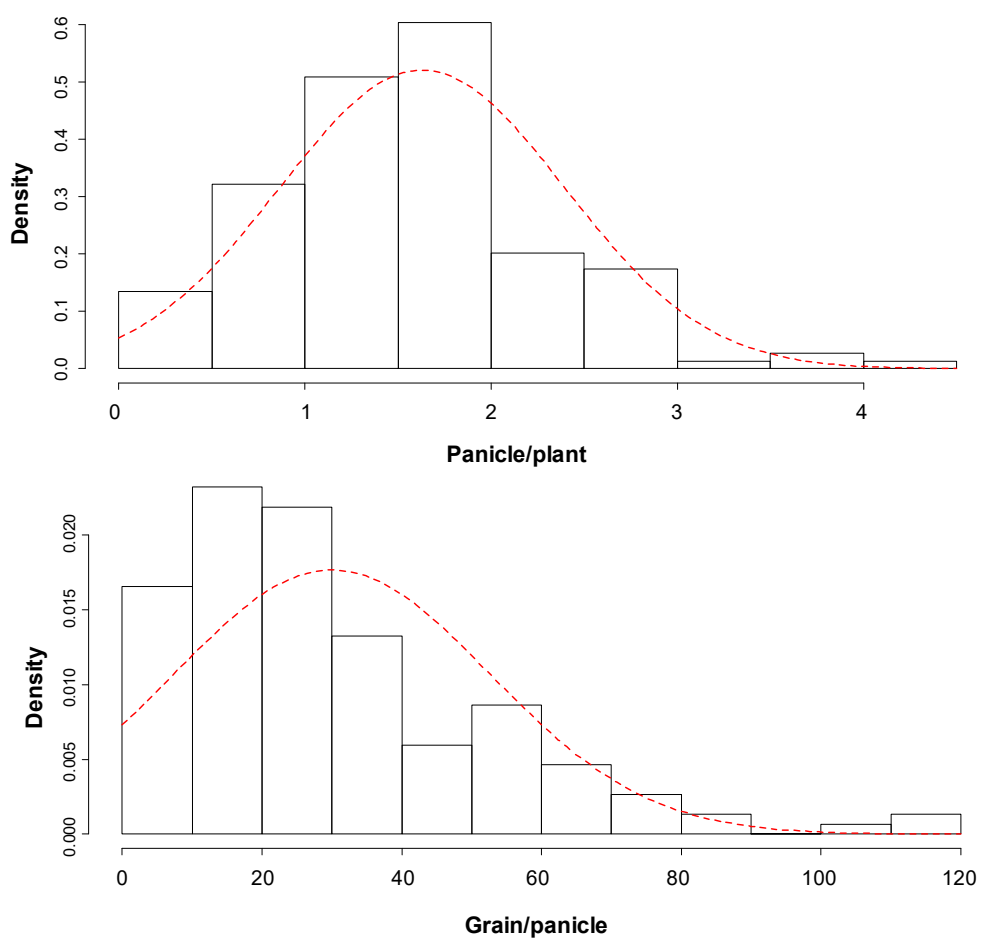

Figure 2. Cont. 


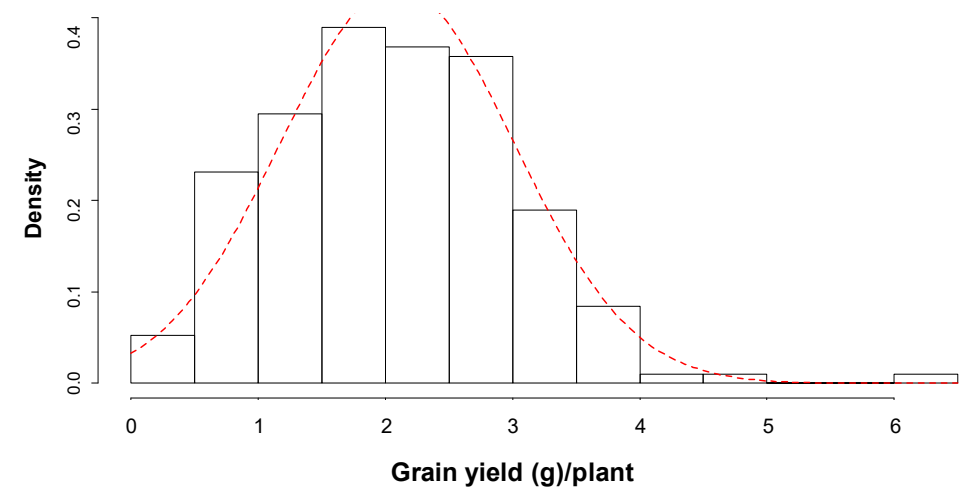

Figure 2. Frequency distribution of yield traits (panicle/plant—upper panel; grain/panicle-middle panel; and grain yield (g)/plant-lower panel) of the $F_{2: 3}$ progenies derived from Cocodrie $\times$ N22 under greenhouse drought conditions. Density $=$ frequency/interval. Frequency $=$ area of the bar representing the number of $\mathrm{F}_{2: 3}$ lines in a class.

\subsection{QTLs Controlling the Yield Traits}

Linkage analysis of 152 markers generated a $1888.6 \mathrm{cM}$-long map, where the average distance between the adjacent markers was $15.1 \mathrm{cM}$ (Supplementary Figure S1). Chromosome 3 was the longest and chromosome 10 was the smallest. The chromosomes had markers distributed over the entire length with some gaps, especially in chromosome 3, 4, 5, 6, 7 and 12. Chromosome 6 had the largest gap of $\sim 22.6 \mathrm{Mbp}$ between RM589 and RM162. The gaps in the chromosomal region were due to the lack of polymorphic markers identified between the parents.

Altogether, eight QTLs were identified by the ICIM for the yield traits under drought stress (Table 1; Supplementary Figure S1). A major QTL on chromosome 1 ( $q$ PN1.1) was found to control panicle number explaining $37.7 \%$ of the total phenotypic variance with the highest LOD (15.1). The QTL was delimited by markers SNPID280 and RD105_2, with a positive additive genetic variance of 2.6, suggesting that $\mathrm{N} 22$ contributed the favorable allele.

Three QTLs, two on chromosome 3 ( $q$ GN3.1 and $q$ GN3.2) and one on chromosome 5 ( $q$ GN5.1), were detected for grain number per panicle. Coincidentally, the phenotypic variance explained by each QTLs were 3.8\% each. While N22 contributed the favorable alleles for qGN3.1, the drought-sensitive parent, Cocodrie contributed the positive alleles for qGN3.2 and qGN5.1.

Four QTLs, one each on chromosome 1 (qGY1.1), 7 (qGY7.1), 8 (qGY8.1) and 11 (qGY11.1), which collectively controlled $45 \%$ of the phenotypic variance, were identified for grain yield under drought by ICIM. Individually, $q G Y 8.1$ explained the maximum phenotypic variance (13.3\%) followed by $q G Y 7.1$ $(12.7 \%), q G Y 1.1(11.1 \%)$ and $q G Y 11.1$ (7.9\%). For all the QTLs, the alleles for increasing mean grain yield were contributed by the drought-resistant parent, N22. QTLs, $q$ GY1.1 and $q P N 1.1$ were co-localized.

In addition to the additive QTLs, six epistatic QTLs were discovered from ICIM (LOD > 5.0) controlling panicle number and grain yield under drought (Supplementary Table S3). Four inter-chromosomal epistatic QTLs were responsible for controlling panicle number with the highest phenotypic variance explained (PVE) (10.1\%) by the interaction of QTLs on chromosome 2 and 12 . Two epistatic QTLs, one between chromosome 1 and 3 and the other between chromosome 9 and 12 controlled grain yield with equal contribution to the PVE (6.5\%). Although an epistatic QTL was identified on chromosome 1, none of the epistatic QTLs overlapped with the additive QTLs. 
Table 1. Quantitative trait loci (QTL) identified for yield traits in $\mathrm{F}_{2: 3}$ progenies derived from Cocodrie $\times$ N22 under greenhouse drought.

\begin{tabular}{|c|c|c|c|c|c|c|c|c|c|c|c|}
\hline Trait & QTL & Chr & Position (cM) & Left Marker & Right Marker & LOD & PVE & Add & Dom & Left CI & Right CI \\
\hline \multicolumn{12}{|c|}{ Panicle/plant } \\
\hline & $q P N 1.1$ & 1 & 279.6078 & SNPID280 & RD0105_2 & 15.104 & 37.732 & 2.566 & -2.6217 & 276.6577 & 282.558 \\
\hline \multicolumn{12}{|c|}{ Grain/panicle } \\
\hline & $q G N 3.1$ & 3 & 31.4001 & RM1278 & RM1867 & 5.956 & 3.824 & 21.694 & -21.3334 & 20.95 & 43.0499 \\
\hline & qGN3.2 & 3 & 130.6988 & RM514 & RM5755 & 4.339 & 3.753 & -21.515 & -21.0113 & 119.8487 & 140.4494 \\
\hline & $q G N 5.1$ & 5 & 107.2989 & RM440 & CVSSR21 & 3.354 & 3.770 & -21.117 & -22.9362 & 104.549 & 114.1488 \\
\hline \multicolumn{12}{|c|}{ Grain yield/plant } \\
\hline & $q G Y 1.1$ & 1 & 287.7083 & SNPID280 & RD0105_2 & 2.787 & 11.147 & 0.983 & -1.395 & 282.7581 & 294.8588 \\
\hline & $q G Y 7.1$ & 7 & 113.8988 & RM10 & RM47 & 2.661 & 12.652 & 0.370 & -1.0751 & 98.5491 & 124.2487 \\
\hline & $q G Y 8.1$ & 8 & 30.6001 & RM22926 & SNPID457 & 5.777 & 13.264 & 0.424 & 0.2553 & 22.8501 & 37.65 \\
\hline & $q G Y 11.1$ & 11 & 111.7989 & SNPID452 & SNPID202 & 3.767 & 7.859 & 0.396 & 0.0759 & 105.349 & 118.3488 \\
\hline
\end{tabular}

$\mathrm{Chr}=$ chromosome; $\mathrm{cM}$ = centi Morgan; $\mathrm{PVE}$ = phenotypic variance explained; $\mathrm{Add}=$ additive; Dom = dominance; $\mathrm{CI}$ = confidence interval. 


\subsection{Allelic Contribution at the Drought Yield Traits QTLS}

Genotype frequency of the $\mathrm{F}_{2: 3}$ lines calculated for the markers closest to the yield traits QTLs showed that the average number of panicles and grain yield of the lines homozygous for the N22 allele at three flanking markers (SNP280, RM457, and RM10) was higher than the homozygous Cocodrie allele (Supplementary Figure S2). On the other hand, the frequency of Cocodrie allele (0.098) and Cocodrie/N22 alleles (0.090) for mean grain yield of the lines were nearly equal at marker closest to qGY11.1 (SNPID202). Lines homozygous with N22 alleles and/or heterozygous at CVSSR21 had higher grains per panicle whereas lines homozygous for Cocodrie allele and/or heterozygous at RM1278 and RM5755 had higher grain number per panicle.

\subsection{Genes Underlying QTL Regions}

Comparison of the genes identified based on the physical location of the markers against known drought responsive genes of N22 and Cocodrie [25,35] showed several genes with known/unknown functions and transposons underlying the QTLs for yield traits under drought stress. Phosphatidylserine decarboxylase DUF630/DUF632 domains containing protein, serine-threonine protein kinase, APETALA2/ethylene-responsive binding protein, trehalose 6-phosphate phosphatase (TPP), aquaporin protein TIP1.2, WD40 (G- $\beta$ ) repeat domain containing protein, purple acid phosphatase, and zinc finger protein are some of the stress-responsive genes that are closely linked (within $10 \mathrm{~Kb}$ distance) to the marker closest to the peak of the yield traits QTLs (Supplementary Table S4).

\section{Discussion}

Drought is an increasing threat to the sustainability of rice production worldwide due to irregular rainfall patterns under the climatic uncertainties. The recent shifts in climate have challenged rice researchers to devise scientific strategies to address this issue, such as to breed new rice varieties that can adapt to periodic dry spells even in areas where water availability for irrigation is considered to be abundant. QTL mapping strategy has been widely used to understand the genetic complexity of quantitative traits such as drought tolerance in rice. Earlier studies suggested direct selection for grain yield as the most effective approach to breeding improved drought-resistant rice varieties $[19,25,36]$. Many previous studies have identified QTLs for grain yield traits under both vegetative- and reproductive-stage drought stress through selective/genome-wide genotyping [12,14-18,25,37-40]. The present study was undertaken to identify genomic regions and the genes that govern rice yield traits under drought in elite US rice germplasm. In the absence of a rain-out shelter to control rainfall under natural conditions, the mapping population was evaluated under controlled greenhouse conditions that can circumvent the variation due to micro (soil) and macro environmental factors [25]. Differential drought response of the mapping population and the parents, Cocodrie and N22, was evident from the phenotypes, such as leaf rolling, leaf drying, and yield metrics (Figure 1; Supplementary Table S1). The moderate broad sense heritability values for yield traits (Supplementary Table S1) presented in this study are in agreement with other studies reported for yield traits under controlled drought conditions $[25,41]$.

A total of eight QTLs that control yield traits under drought response were identified in chromosomes 1, 3, 5, 7, 8, and 11 in the present study. However, none of the 16 QTLs [10] and seven meta-QTLs [11] reported earlier were identified in chromosome 7 and 8. QTLs associated with yield traits are often co-localized [14,19,42], and in the present study a single QTL on chromosome 1 (SNPID280 and RD0105_2) contributed to both panicle number and grain yield under drought. However, QTLs for drought tolerance secondary traits could also contribute to the yield under drought [6].

The marker SNPID280 associated with QTLs $q$ GY1.1 and $q P N 1.1$ on chromosome 1 (42.32 Mbp) for grain yield and panicle number, respectively, under drought, in our study was co-localized with 
the known grain yield QTLs reported earlier $[15,16]$. The chromosomal region harboring $q G Y 1.1$ also harbors the $s d 1$ gene for semi-dwarf plant height, suggesting the relevance of the 'green revolution gene' in drought stress response in rice [43,44]. The same genomic region harbors the single major QTL (37.732\% PVE) identified for panicle number (productive tillers) under drought. However, $q$ GY1.1 did not overlap with the grain yield QTL reported earlier on chromosome 1 in a population derived from Cocodrie and Vandana [25] where favorable alleles were contributed by the susceptible parent Cocodrie in contrast to N22 in the present study. Such observations underscore the importance of genetic background in favorable allele discovery. Due to high positive correlation between the yield components such as panicle number and grain yield under drought, and negative correlation with plant height, QTLs for different yield-related traits co-localize in the same or closely linked chromosomal regions [44].

The grain yield QTL, $q$ GY7.1 (RM 10-RM47) identified on chromosome 7 in this study spanned qYP7.2 (RM1377-RM1279), the QTL reported for grain yield per plant under drought [45]. Chromosome 7 was also found to contain a QTL for the yield attributing trait, spikelet fertility from a greenhouse drought study involving an independent set of population from the same parents [16]. The QTL on chromosome 7, qGY7.1 identified in this study was not discovered in the Cocodrie $\times$ Vandana population that we reported earlier [25].

The QTL on chromosome 8 (RM22926-SNPID457) explained the highest phenotypic variance $(13.26 \%)$ for grain yield (Table 1). This QTL was co-localized with the yield QTL under greenhouse drought conditions that we reported earlier using the population derived from Cocodrie and Vandana [25]. The genomic region also overlapped with the metaQTL MQTL8.2 [11]. The QTL, qGY8.1 for grain yield under aerobic conditions [46] and $q D T Y 8.1$ under drought stress [47] are co-localized between RM339 and RM210, close to regions harboring QTLs for other yield related traits and root length [46]. Genome-wide association studies also identified the marker RM6070 of chromosome 8 to be significantly associated $(p<0.01)$ with both plant height $\left(R^{2}=3.96\right)$ and percentage seed set $\left(R^{2}=12.85 \%\right)$ [48]. A major QTL located on chromosome 8 explaining $54 \%$ of the phenotypic variance for grain yield was reported in Swarna $\times$ Oryza nivara population [49]. Thus, chromosome 8 appears to be a hot spot for alleles with positive effects on yield traits under drought. However, the QTL peak detected in the present study did not co-localize with the QTLs reported on chromosome 8 earlier by Prince et al. [50] under target environments.

The QTL $q$ GY11.1 on chromosome 11 (SNPID452-SNPID202) that explained 7.86\% of the variance for grain yield has not been reported earlier for grain yield under drought. However, a QTL qSF11.19 (19.37 Mbp) [16] identified to control spikelet fertility under drought stress is located $\sim 4 \mathrm{Mbp}$ apart from the SNPID452 (23.9 Mbp). On the other hand, a QTL for deep root length under drought was observed between 9.0 Mbp (RM202) and 18.4 Mbp (RM229) on chromosome 11 [51] in the proximity of qGY11.1.

Favorable alleles for the number of grains per panicle were contributed by the drought-resistant parent N22 for $q$ GN3.2 (RM514-RM5755) as well as the drought-sensitive parent Cocodrie for $q$ GN3.1 (RM1278-RM1867). The QTL $q$ GN3.2 covered the metaQTL MQTL3.2 reported for grain yield under stress [11]. MQTL3.1 (1.3 Mbp) and a QTL at RM232 (1.0 Mbp) for single plant yield under drought stress [52] were also found close to the grain number QTL qGN3.1 (4.5 Mbp) identified in the present study. However, no QTL for yield traits under drought was identified on chromosome 3 in managed stress and target environments [50] and in our previous controlled drought treatment study [25]. However, a QTL at 33.1 Mbp for \% plant dry matter content [16] and QTLs for total shoot dry weight, leaf/stem dry weight, deep root length at RM520 (30.9 Mbp) were reported nearby RM514 (35.2 Mbp) [51] delimiting $q G N 3.2$.

The region between RM440-CVSSR21 on chromosome 5 was also found to be consistent for yield traits under drought stress. It harbored qGN5.1 for the number of grains per panicle in the present study whereas it directly controlled the grain yield in our previous study [25]. Wang et al. [53] identified four QTLs between S4134205-S7643153 of chromosome 5 that controlled grain yield and related traits in 
two genetic backgrounds and different environments whereas Yue et al. [54] identified a minor QTL for test weight under drought between RM509-RM430. However, none of these regions overlapped with $q G N 5.1$ or $q G Y 5.1$ [25].

In contrast to the QTL12.1 for high grain yield under drought that was identified in the $\mathrm{F}_{3}$ population of Vandana/Way Rarem and contributed by the drought-sensitive parent Way Rarem [12], none of the QTLs in the present study were identified on chromosome 12 for grain yield under drought. On the other hand, consistent with our previous report [25], a QTL for grain yield was identified under non-stressed (well-watered) control condition, where the favorable allele was contributed by the drought-sensitive parent Cocodrie (Supplementary Figure S1). Such observations were also documented before, where the QTL region reported for grain yield under drought on chromosome 8 [11] overlapped QTL8.1 (RM337-RM3664; peak RM8020) that was associated with grain yield under well-watered upland conditions [12].

Most genes identified underlying the QTL regions are known to be responsive to abiotic stress, especially drought. While TPP (LOC_Os02g548200) and serine-threonine protein kinase (LOC_Os06g18820) were not differentially expressed in N22 relative to IR64 [35], Solis et al. [25] reported a 2.53-fold and 5.45-fold increase in their expression in the drought-tolerant variety Vandana relative to the drought-sensitive variety Cocodrie. However, there was no change in expression of phosphatidylserine decarboxylase (LOC_Os01g72940), WD40 protein (LOC_Os03g08830), and zinc finger protein (LOC_Os03g08840) in either N22 or Vandana under stress relative to the drought-sensitive varieties. DUF630/DUF632 domains containing protein (LOC_Os01g72970) and EREB (LOC_Os08g31580) were upregulated in N22 by 4.37-fold and 1.47-fold, respectively, under desiccation stress [35]. Recently, there are reports of genes linked to QTLs expressed under drought stress $[16,25,50]$. The genes and associated gene networks identified under stress will enhance our ability to understand drought response mechanisms and utilize the knowledge to improve grain yield under drought stress.

Controlled drought stress treatment in potted plants under greenhouse conditions could circumvent the problems associated with field conditions, such as variation in soil texture, soil temperature, and other environmental factors, such as humidity, disease and insect pressures that confound phenotyping and consistent QTL detection. However, grain yield QTLs under controlled greenhouse drought conditions may not be expressed under target field environments [55] as plant traits will vary in their response with varying timing and severity of drought under the rainfed rice ecosystem $[50,56,57]$. For example, there may not be significant correlation between QTLs for drought tolerance traits in upland and low land rice varieties [58] due primarily to the change in hydrology where soil transitions from flooded and anaerobic to drought and aerobic [59]. However, large-effect QTLs, such as deeper rooting 1 (DRO1) that confers drought resistance in paddy fields with enhanced yield [60] was identified under controlled conditions drought [61]. Further, consistency in the expression of the major-effect grain yield QTL on chromosome 1 under field drought conditions $[15,17]$ and greenhouse drought conditions in the present study and earlier reports [16,25] suggest that in the absence of a rain-out shelter, precise maintenance of the soil moisture content for (controlled) greenhouse drought conditions could successfully be exploited for the identification of QTL regions controlling grain yield under stress. In addition to chromosome 1, QTLs on chromosome 5 and 8 identified in the present study and our previous study [25] under greenhouse drought conditions indicate that these QTLs will also most likely be expressed under drought field conditions.

A successful marker-assisted breeding to improve grain yield under drought will depend on the identification and consistent expression of large-effect QTLs under natural drought conditions in various target field environments $[18,62]$. To this end, we are currently evaluating our advanced generation recombinant inbred lines under controlled field drought conditions and/or aerobic conditions to validate the consistency of identified yield traits QTLs and to precisely identify causal genes for the subsequent development of diagnostic markers. Our present research represents findings from the ongoing efforts to develop rice varieties that will have little to no yield penalty under periodic dry 
spells (such as aerobic conditions) in furrow-irrigated (row) rice in southern U.S., such as in Louisiana, Arkansas, Texas, and Mississippi.

Supplementary Materials: The following are available online at http://www.mdpi.com/2073-4425/11/1/62/s1. Figure S1: Linkage maps of $\mathrm{F}_{2: 3}$ progenies derived from Cocodrie $\times$ N22. Quantitiative trait loci (QTLs) controlling yield traits under greenhouse drought and control conditions are shown on chromosomes 1, 3, 5, 7, 8, 9, 11 and 12. QTLs in green, blue and red represent genomic regions associated with panicle number, grain number, and grain yield, respectively, under drought conditions. QTLs in orange and purple are associated with grain number and grain yield, respectively, under non-stress control. Figure S2: Genotype frequency of the $\mathrm{F}_{2: 3}$ progenies derived from Cocodrie $\times \mathrm{N} 22$ at the marker closest to the genomic regions associated with grain yield traits under greenhouse drought conditions. A, Cocodrie; $\mathrm{H}$, heterozygous; $\mathrm{B}, \mathrm{N} 22$. Table S1: Yield traits of $\mathrm{F}_{2: 3}$ progenies derived from Cocodrie $\times$ N22 under greenhouse drought. Table S2: Correlation between yield traits of $F_{2: 3}$ progenies derived from Cocodrie $\times$ N22 under greenhouse drought. Table S3: Epistatic quantitative trait loci controlling panicle number and grain yield of $\mathrm{F}_{2: 3}$ progenies derived from Cocodrie $\times \mathrm{N} 22$ under greenhouse drought. Table S4: Genes within $10 \mathrm{~Kb}$ of the marker closest to the QTL peak for the yield traits.

Author Contributions: N.B. conceptualized and designed the experiment; N.B., V.M., J.Y., P.M., and A.F. performed the experiments. N.B. and A.G. analyzed the data. N.B., A.P., and A.F. contributed to manuscript writing and revision. All authors have read and agreed to the published version of the manuscript.

Funding: The research was funded by the National Science Foundation award DBI-0922747), United States Department of Agriculture - National Institute of Food and Agriculture award VAR-2008-01133, and the Louisiana Rice Research Board award GRC-9401441120000000. P.M was funded by a fellowship from the Foundation for Studying Abroad of Jiangsu Province (PR China).

Acknowledgments: The authors thank Brijesh Angira, Rice Research Station, for his technical help with SNP genotyping. The manuscript has been approved for publication by the Louisiana Agricultural Experiment Station as manuscript \# 2019-306-34221.

Conflicts of Interest: The authors declare no conflict of interest.

\section{References}

1. Sandhu, K.S.; You, F.M.; Conner, R.L.; Balasubramanian, P.M.; Hou, A. Genetic Analysis and QTL Mapping of the Seed Hardness Trait in a Black Common Bean (Phaseolus vulgaris) Recombinant Inbred Line (RIL) Population. Mol. Breed. 2018, 38, 34. [CrossRef]

2. Sandhu, N.; Kumar, A. Bridging the Rice Yield Gaps under Drought: QTLs, Genes, and Their Use in Breeding Programs. Agron. J. 2017, 7, 27. [CrossRef]

3. Qin, F.; Shinozaki, K.; Yamaguchi-Shinozaki, K. Achievements and challenges in understanding plant abiotic stress responses and tolerance. Plant Cell Physiol. 2011, 52, 1569-1582. [CrossRef]

4. Kumar, A.; Bernier, J.; Verulkar, S.; Lafitte, H.R.; Atlin, G.N. Breeding for Drought Tolerance: Direct Selection for Yield, Response to Selection and Use of Drought-Tolerant Donors in Upland and Lowland-Adapted Populations. Field Crops Res. 2008, 107, 221-231. [CrossRef]

5. Baisakh, N.; Famoso, A.; Yabes, J.; Tabien, R.; Harrell, D. Developing rice varieties suitable for alternative irrigation regime in Louisiana. La. Agric. 2019, 62, 18-19.

6. Swain, P.; Anumalla, M.; Prusty, S.; Marndi, B.C.; Rao, G.J.N. Characterization of some Indian native land race rice accessions for drought tolerance at seedling stage. Aust. J. Crop Sci. 2014, 8, 324-331.

7. Collins, N.C.; Tardieu, F.; Tuberosa, R. Quantitative trait loci and crop performance under abiotic stress: Where do we stand? Plant Physiol. 2008, 147, 469-486. [CrossRef]

8. Ashraf, M. Inducing drought tolerance in plants: Recent advances. Biotechnol. Adv. 2010, 28, 169-183. [CrossRef]

9. Kumar, S.; Sachdeva, S.; Bhat, K.V.; Vats, S. Plant Responses to Drought Stress: Physiological, Biochemical and Molecular Basis. In Biotic and Abiotic Stress Tolerance in Plants; Vats, S., Ed.; Springer Nature: Singapore, 2018.

10. Kumar, A.; Dixit, S.; Ram, T.; Yadaw, R.B.; Mishra, K.K.; Mandal, N.P. Breeding High-Yielding Drought-Tolerant Rice: Genetic Variations and Conventional and Molecular Approaches. J. Exp. Bot. 2014, 65, 6265-6278. [CrossRef]

11. Swamy, B.P.M.; Vikram, P.; Dixit, S.; Ahmed, H.U.; Kumar, A. Meta-Analysis of Grain Yield QTL Identified during Agricultural Drought in Grasses Showed Consensus. BMC Genom. 2010, 12, 319. [CrossRef] 
12. Bernier, J.; Kumar, A.; Ramaiah, V.; Spaner, D.; Atlin, G.N. A Large-Effect QTL for Grain Yield under Reproductive-Stage Drought Stress in Upland Rice. Crop Sci. 2007, 47, 507-516. [CrossRef]

13. Bernier, J.; Kumar, A.; Venuprasad, R.; Spaner, D.; Verulkar, S.; Mandal, N.P.; Sinha, P.K.; Peeraju, P.; Dongre, P.R.; Mahto, R.N.; et al. Characterization of the Effect of a QTL for Drought Resistance in Rice, qtl12.1, over a Range of Environments in the Philippines and Eastern INDIA. Euphytica 2009, 166, 207-217. [CrossRef]

14. Mishra, K.K.; Vikram, P.; Yadaw, R.B.; Swamy, B.P.M.; Dixit, S.; Cruz, M.T.S.; Maturan, P.; Marker, S.; Kumar, A. qDTY12.1: A Locus with a Consistent Effect on Grain Yield under Drought in Rice. BMC Genet. 2013, 14. [CrossRef] [PubMed]

15. Vikram, P.; Swamy, B.P.M.; Dixit, S.; Ahmed, H.; Cruz, M.T.; Singh, A.K.; Kumar, A. qDTY1.1, a Major QTL for Rice Grain Yield under Reproductive-Stage Drought Stress with a Consistent Effect in Multiple elite Genetic Backgrounds. BMC Genet. 2011, 12. [CrossRef]

16. Bhattarai, U.; Subudhi, P.K. Genetic Analysis of Yield and Agronomic Traits under Reproductive-Stage Drought Stress in Rice Using a High-Resolution Linkage Map. Gene 2018, 669, 69-76. [CrossRef]

17. Ghimire, K.H.; Quiatchon, L.A.; Vikram, P.; Swamy, B.P.M.; Dixit, S.; Ahmed, H.; Hernandez, J.E.; Borromeo, T.H.; Kumar, A. Identification and Mapping of a QTL (qDTY1.1) with a Consistent Effect on Grain Yield under Drought. Field Crops Res. 2012, 131, 88-96. [CrossRef]

18. Yadaw, R.B.; Dixit, S.; Raman, A.; Mishra, K.K.; Vikram, P.; Swamy, B.P.M.; Cruz, M.T.S.; Maturan, P.T.; Pandey, M.; Kumar, A. A QTL for High Grain Yield under Lowland Drought in the Background of Popular Rice Variety SABITRI from Nepal. Field Crops Res. 2013, 144, 281-287. [CrossRef]

19. Saikumar, S.; Gouda, K.P.; Saiharini, A.; Varma, C.M.K.; Vineesha, O.; Padmavathi, G.; Shenoy, V.V. Major QTL for Enhancing Rice Grain Yield under Lowland Reproductive Drought Stress Identified Using an $O$. sativa/O. glaberrima Introgression Line. Field Crops Res. 2014, 163, 119-131. [CrossRef]

20. Tang, S.Q.; Shao, G.N.; Wei, X.J.; Chen, M.L.; Shen, Z.H.; Luo, J.; Jiao, G.A.; Xie, L.H.; Hu, P.S. QTL Mapping of Grain Weight in Rice and the Validation of the QTL qTGW3.2. Gene. 2013, 527, 201-206. [CrossRef]

21. Dixit, S.; Swamy, B.P.M.; Vikram, P.; Bernier, J.; Cruz, M.T.; Amante, M.; Atri, D.; Kumar, A. Increased drought tolerance and wider adaptability of $q D T Y 12.1$ conferred by its interaction with $q D T Y 2.3$ and qDTY 3.2. Mol. Breed. 2012, 30, 1767-1779. [CrossRef]

22. Lang, N.T.; Nha, C.T.; Ha, P.T.T.; Buu, B.C. Quantitative Trait Loci (QTLs) Associated with Drought Tolerance in Rice (Oryza sativa L.). SABRAO J. Breed. Genet. 2013, 45, 409-421.

23. Zhang, Y.D.; Zhang, Y.H.; Dong, S.L.; Chen, T.; Zhao, Q.Y.; Zhu, Z.; Zhou, L.H.; Yao, S.; Zhao, L.; Yu, X.; et al. QTL Mapping for Grain Size Traits Based on Extra-Large Grain Rice Line TD70. Rice Sci. 2014, 20, 400-406. [CrossRef]

24. Dilday, R.H. Contribution of Ancestral Lines in the Development of New Cultivars of Rice. Crop Sci. 1990, 30, 905-911. [CrossRef]

25. Solis, J.; Gutierrez, A.; Mangu, V.; Sanchez, E.; Bedre, R.; Linscombe, S.; Baisakh, N. Genetic Mapping of Quantitative Trait Loci for Grain Yield under Drought in Rice under Controlled Greenhouse Conditions. Front. Chem. 2018, 5, 129. [CrossRef]

26. Linscombe, S.D.; Jodari, F.; Bollich, P.K.; Groth, D.E.; White, L.M.; Chu, Q.R.; Dunand, R.T.; Sanders, D.E. Registration of "Cocodrie" Rice. Crop Sci. 2000, 40, 294. [CrossRef]

27. Jagadish, S.V.; Muthurajan, R.; Oane, R.; Wheeler, T.R.; Heuer, S.; Bennett, J.; Craufurd, P.Q. Physiological and Proteomic Approaches to Address Heat Tolerance during Anthesis in Rice (Oryza sativa L.). J. Exp. Bot. 2010, 61, 143-156. [CrossRef]

28. Batlang, U.; Baisakh, N.; Ambavaram, M.M.R.; Pereira, A. Phenotypic and Physiological Evaluation for Drought and Salinity Stress Responses in Rice. In Rice Protocols. Methods in Molecular Biology (Methods and Protocols); Yang, Y., Ed.; Humana Press: Totowa, NJ, USA, 2013; Volume 956. [CrossRef]

29. SAS Institute. SAS 9.3; SAS Institute Inc.: Cary, NC, USA, 2011.

30. Gutierrez, A.F. Development of Functional Markers for Resistance to Leaf Scald in Sugarcane; [Dissertation/doctoral dissertation etd-11102016-152405]; Louisiana State University: Baton Rouge, LA, USA, 2016; pp. 57-58.

31. McCouch, S.R.; Teytelman, L.; Xu, Y.; Lobos, K.B.; Clare, K.; Walton, M.; Fu, B.; Maghirang, R.; Li, Z.; Xing, Y.; et al. Development and Mapping of 2240 New SSR Markers for Rice (Oryza sativa L.). DNA Res. 2002, 9 , 199-207. [CrossRef] 
32. Wu, D.-H.; Wu, H.-P.; Wang, C.-S.; Tseng, H.-Y.; Hwu, K.-K. Genome-Wide InDel Marker System for Application in Rice Breeding and Mapping Studies. Euphytica 2013, 192, 131-143. [CrossRef]

33. Wang, J.; Li, H.; Zhang, L.; Meng, L. Users' Manual of QTL IciMapping; The Quantitative Genetics Group, Institute of Crop Science, Chinese Academy of Agricultural Sciences (CAAS): Beijing, China; Genetic Resources Program, International Maize and Wheat Improvement Center (CIMMYT): Mexico City, Mexico, 2014.

34. Mansueto, L.; Fuentes, R.R.; Borja, F.N.; Detras, J.; Abriol-Santos, J.M.; Chebotarov, D.; Sanciangco, M.; Palis, K.; Copetti, D.; Poliakov, A. Rice SNP-Seek Database Update: New SNPs, Indels, and Queries. Nucleic Acids Res. 2017, 45, D1075-D1081. [CrossRef]

35. Shankar, R.; Bhattacharjee, A.; Jain, M. Transcriptome Analysis in Different Rice Cultivars Provides Novel Insights into Desiccation and Salinity Stress Responses. Sci. Rep. 2016, 6, 23719. [CrossRef]

36. Dixit, S.; Singh, A.; Kumar, A. Rice Breeding for High Grain Yield under Drought: A Strategic Solution to a Complex Problem. Int. J. Agron. 2014, 2014. [CrossRef]

37. Lanceras, J.C.; Pantuwan, G.; Jongdee, B.; Toojinda, T. Quantitative Trait Loci Associated with Drought Tolerance at Reproductive Stage in Rice. Plant Physiol. 2004, 135, 384-399. [CrossRef]

38. Venuprasad, R.; Dalid, C.O.; Del Valle, M.; Zhao, D.; Espiritu, M.; Cruz, M.T.; Amante, M.; Kumar, A.; Atlin, G.N. Identification and Characterization of Large-Effect Quantitative Trait Loci for Grain Yield under Lowland Drought Stress in Rice Using Bulk-Segregant Analysis. Theor. Appl. Genet. 2009, 120, 177-190. [CrossRef]

39. Swamy, B.P.M.; Ahmed, H.U.; Henry, A.; Mauleon, R.; Dixit, S.; Vikram, P.; Tilatto, R.; Verulkar, S.B.; Perraju, P.; Mandal, N.P.; et al. Genetic, Physiological, and Gene Expression Analyses Reveal that Multiple QTL Enhance Yield of Rice Mega-Variety IR64 under Drought. PLoS ONE 2013, 8, e62795. [CrossRef]

40. Sandhu, N.; Singh, A.; Dixit, S.; Sta Cruz, M.T.; Maturan, P.C.; Kumar, R.; Kumar, A. Identification and Mapping of Stable QTL with Main and Epistasis Effect on Rice Grain Yield under Upland Drought Stress. BMC Genet. 2014, 15, 63. [CrossRef]

41. Manickavelu, A.; Nadarajan, N.; Ganesh, S.K.; Gnanamalar, R.P.; Babu, R.C. Drought Tolerance in Rice: Morphological and Molecular Genetic Consideration. Plant Growth Regul. 2006, 50, 121-138. [CrossRef]

42. Venuprasad, R.; Bool, M.E.; Quiatchon, L.; Cruz, M.T.; Amante, M.; Atlin, G.N. A Large-Effect QTL for Rice Grain Yield under Upland Drought Stress on Chromosome 1. Mol. Breed. 2012, 30, 535-547. [CrossRef]

43. Trijatmiko, K.R.; Prasetiyono, S.K.; Thomson, M.J.; Vera Cruz, C.M.; Moeljopawiro, S.; Pereira, A. Meta-Analysis of Quantitative Trait Loci for Grain Yield and Component Traits under Reproductive-Stage Drought Stress in an Upland Rice Population. Mol. Breed. 2014, 34, 283-295. [CrossRef]

44. Vikram, P.; Swamy, B.P.M.; Dixit, S.; Singh, R.; Singh, B.P.; Miro, B.; Kohli, A.; Henry, A.; Singh, N.K.; Kumar, A. Drought Susceptibility of Modern Rice Varieties: An Effect of Linkage of Drought Tolerance with Undesirable Traits. Sci. Rep. 2015, 5, 14799. [CrossRef]

45. Xing, W.; Zhao, H.; Zou, D. Detection of Main-Effect and Epistatic QTL for Yield-Related Traits in Rice under Drought Stress and Normal Conditions. Can. J. Plant Sci. 2014, 94, 633-641. [CrossRef]

46. Sandhu, N.; Jain, S.; Kumar, A.; Mehla, B.S.; Jain, R. Genetic Variation, Linkage Mapping of QTL and Correlation Studies for Yield, Root, and Agronomic Traits for Aerobic Adaptation. BMC Genet. 2013, 14. [CrossRef]

47. Vikram, P.; Swamy, B.P.M.; Dixit, S.; Ahmed, H.; Cruz, M.T.; Singh, A.K.; Ye, G.; Kumara, A. Bulk Segregant Analysis: "An Effective Approach for Mapping Consistent-Effect Drought Grain Yield QTLs in Rice.". Field Crops Res. 2012, 134, 185-192. [CrossRef]

48. Zhou, J.; You, A.; Ma, Z.; Zhu, L.; He, G. Association Analysis of Important Agronomic Traits in Japonica Rice Germplasm. Afr. J. Biotechnol. 2012, 11, 2957-2970. [CrossRef]

49. Kaladhar, K.; Swamy, B.P.M.; Babu, A.P.; Reddy, C.; Sarala, N. Mapping Quantitative Trait Loci for Yield Traits in $\mathrm{BC}_{2} \mathrm{~F}_{2}$ Population Derived from "Swarna" x O. Nivara Cross. Rice Genet Newslett. 2008, 24, 34-36.

50. Prince, S.J.; Beena, R.; Gomez, S.M.; Senthivel, S.; Babu, R.C. Mapping Consistent Rice (Oryza sativa L.) Yield QTLs under Drought Stress in Target Rainfed Environments. Rice 2015, 8, 25. [CrossRef]

51. Sabar, M.; Shabir, G.; Shah, S.M.; Aslam, K.; Naveed, S.A.; Arif, M. Identification and Mapping of QTLs Associated with Drought Tolerance Traits in Rice by a Cross between Super Basmati and IR55419-04. Breed. Sci. 2019, 69, 169-178. [CrossRef] 
52. Subashri, M.; Robin, S.; Vinod, K.K.; Rajeswari, S.; Mohanasundaram, K.; Raveendran, T.S. Trait Identification and QTL Validation for Reproductive Stage Drought Resistance in Rice Using Selective Genotyping of Near Flowering RILs. Euphytica 2009, 166, 291. [CrossRef]

53. Wang, X.; Pang, Y.; Zhang, J.; Tao, Y.; Feng, B.; Zheng, T.; Xu, J.; Li, Z. Genetic Background Effects on QTL and QTL $\times$ Environment Interaction for Yield and Its Component Traits as Revealed by Reciprocal Introgression Lines in Rice. Crop, J. 2014, 2, 345-357. [CrossRef]

54. Yue, B.; Xue, W.; Xiong, L.; Yu, X.; Luo, L.; Cui, K.; Jin, D.; Xing, Y.; Zhang, Q. Genetic Basis of Drought Resistance at Reproductive Stage in Rice: Separation of Drought Tolerance from Drought Avoidance. Genetics 2006, 172, 1213-1228. [CrossRef]

55. Weber, V.S.; Melchinger, A.E.; Magorokosho, C.; Makumbi, D.; Banziger, M.; Atlin, G.N. Efficiency of Managed-Stress Screening of Elite Maize Hybrids under Drought and Low Nitrogen for Yield under rainfed Conditions in South Africa. Crop Sci. 2012, 52, 1011-1020. [CrossRef]

56. Pandey, S.; Bhandari, H.; Ding, S.; Prapertchob, P.; Sharan, R.; Naik, D.; Taunk, S.K.; Sastri, A. Coping with Drought in Rice Farming in Asia: Insights from a Cross-Country Comparative Study. Agric. Econ. 2007, 37, 213-224. [CrossRef]

57. Kamoshita, A.; Babu, R.C.; Boopathi, N.; Fukai, S. Phenotypic and Genotypic Analysis of Drought-Resistance Traits for Development of Rice Cultivars Adapted to Rainfed Environments. Field Crops Res. 2008, 109, 1-23. [CrossRef]

58. Mackill, D.J.; Coffman, W.R.; Garrity, D.P. Rainfed lowland Rice Improvement; International Rice Research Institute: Manila, Philippines, 1996; p. 242.

59. Wade, L.J.; McLaren, C.G.; Quintana, L.; Harnpichitvitaya, D.; Rajatasereekul, S.; Sarawgi, A.K.; Kumar, A.; Ahmed, H.U.; Singh, A.K.; Rodriguez, R.; et al. Genotype by Environment Interactions in Diverse Rainfed Lowland Rice Environment. Field Crops Res. 1999, 64, 35-50. [CrossRef]

60. Arai-Sanoh, Y.; Takai, T.; Yoshinaga, S.; Nakano, H.; Kojima, M.; Sakakibara, H.; Kondo, M.; Uga, Y. Deep Rooting Conferred by DEEPER ROOTING 1 Enhances Rice Yield in Paddy Fields. Sci. Rep. 2015, 4, 5563. [CrossRef]

61. Uga, Y.; Okuno, K.; Yano, M. Dro1, a Major QTL Involved in Deep Rooting of Rice under Upland Field Conditions. J. Exp. Bot. 2011, 62, 2485-2494. [CrossRef]

62. Serraj, R.; McNally, K.; Slamet-Loedin, I.; Kohli, A.; Haefele, S.; Atlin, G.; Kumar, A. Drought Resistance Improvement in Rice: An Integrated Genetic and Resource Management Strategy. Plant Prod. Sci. 2011, 14, 1-14. [CrossRef]

(C) 2020 by the authors. Licensee MDPI, Basel, Switzerland. This article is an open access article distributed under the terms and conditions of the Creative Commons Attribution (CC BY) license (http://creativecommons.org/licenses/by/4.0/). 